IZA DP No. 5467

Motivations for Remittances: Evidence from Moldova

Matloob Piracha

Amrita Saraogi

January 2011

Forschungsinstitut zur Zukunft der Arbeit Institute for the Study of Labor 


\title{
Motivations for Remittances: Evidence from Moldova
}

\author{
Matloob Piracha \\ University of Kent \\ and IZA
}

\author{
Amrita Saraogi \\ University of Kent
}

\section{Discussion Paper No. 5467 \\ January 2011}

IZA

P.O. Box 7240

53072 Bonn

Germany

Phone: +49-228-3894-0

Fax: +49-228-3894-180

E-mail: iza@iza.org

Any opinions expressed here are those of the author(s) and not those of IZA. Research published in this series may include views on policy, but the institute itself takes no institutional policy positions.

The Institute for the Study of Labor (IZA) in Bonn is a local and virtual international research center and a place of communication between science, politics and business. IZA is an independent nonprofit organization supported by Deutsche Post Foundation. The center is associated with the University of Bonn and offers a stimulating research environment through its international network, workshops and conferences, data service, project support, research visits and doctoral program. IZA engages in (i) original and internationally competitive research in all fields of labor economics, (ii) development of policy concepts, and (iii) dissemination of research results and concepts to the interested public.

IZA Discussion Papers often represent preliminary work and are circulated to encourage discussion. Citation of such a paper should account for its provisional character. A revised version may be available directly from the author. 
IZA Discussion Paper No. 5467

January 2011

\section{ABSTRACT}

\section{Motivations for Remittances: Evidence from Moldova*}

This paper explores the factors that account for the receipt of remittances across households in Moldova who have migrants abroad. Unlike most of the existing literature, we approach our research question from the perspective of the recipient household and use it to interpret the determinants/motivations of remittances. Our results show that a combination of household and migrant characteristics and some community level variables are the key elements in explaining the remittance behaviour in Moldova. Drawing from these estimates, we conclude that altruism and investment (proxied by the level of economic development at the regional level) are the two main motives behind remittance flows to Moldova.

JEL Classification: F22, F24

Keywords: remittances, migration, Moldova

Corresponding author:

Matloob Piracha

School of Economics

Keynes College

University of Kent

Canterbury, Kent CT2 7NP

United Kingdom

E-mail: M.E.Piracha@kent.ac.uk

\footnotetext{
* We are grateful to Jagjit Chadha, Florin Vadean and Yu Zhu for their detailed comments on an earlier draft of this paper.
} 


\section{Introduction}

International migration can potentially create significant financial and social benefits for migrants, their families, the destination country and the country of origin. Migrants benefit if the net return to their skills is higher in the host country than in their home country while their families benefit from increased consumption and investment as a result of remittances sent by migrants. Furthermore, immigration of workers allows receiving countries to fill their labour market shortages while from the sending country's perspective one of the main benefits of migration stems from the transfer of money from migrants to their families at home, which has a positive effect on the balance of payments.

Notwithstanding the several benefits of migration, a large strand of literature has also highlighted the negative aspects as well, primarily that of the brain drain. However, one argument put forward is that the remittance flow from migrants to the home country tends to compensate for any human capital loss. This flow of money across borders has profound social and economic impacts on various aspects of the home economies. In particular, remittances promote access to financial services for the sender and the recipient, thereby increasing financial and social inclusion. For many countries, remittances form the main source of external finance after foreign direct investment and make up between 5 and 30 percent of their GDP. Given this, understanding the factors that determine this flow of money is important to analyse and contextualise the net benefits of migration.

The analysis of the variation in remittance flows can be approached from different frames of references. One of the most popular and widely used is the framework outlined by Lucas and Stark (1985) who explored the motivations underlying these flows. The motivations to remit can be explained as a combination of economic and social motivations, such as self-interest, altruism, investment, loan repayment and bequest motives, which determine the transfer of resources between the migrants and the household members at home. These transfers can serve varied purposes in households, such as meeting the basic needs of the family at home; serving as payments for services rendered to migrant; payoffs of an insurance scheme that protects recipients from income shocks; returns on the investments made by the household in the migrant's human capital; migrant's investment in inheritable assets; or various other combinations thereof. The role these transfers play in the household determines the motives 
underlying them and hence can provide an 'entry-point' to understand the complexity of household arrangements involved in migration.

However, despite the vast existing literature on remittance behaviour, there is limited research of this aspect for Eastern European countries, particularly those with very high outmigration rate. We fill this gap in the literature by analysing the determinants of remittances from Moldova, which differs in one key aspect from the traditional migration countries -most of the migration from this region is temporary or circular in nature, rather than permanent. As highlighted by Dustmann and Mestres (2010), the form of migration plays an important role on the motivations to remit as those who plan to return to the home country have a different objective of migration than those who plan to stay permanently in the destination country.

It is estimated that approximately 770,000 Moldovans live and work abroad, which represents over half of the economically active population (labour force in 2008 was 1.4 million) and about 21 percent of the total population of Moldova. ${ }^{1}$ Remittances are estimated to be around 31 percent of GDP for the year 2008, which is almost twice the figure in 2002 and is about eight times the foreign direct investment and seven times the official development aid the country receives. As is clear from Fig 1, the share of remittances in GDP since 2006 has been in excess of 30 percent, reflecting the massive dependence of the country on these transfers.

In the backdrop of this, the main aim of the paper is to analyse the factors that play an important role in determining the probability and the amount of remittances received by household's from migrants who are currently abroad. The data set we use was drawn from the survey commissioned by the Centre for Public Opinion Study, CBS AXA and International Organisation for Migration. The survey was conducted between June and August 2006 and contains detailed information on the household and their emigrant family members. The focus is on those households who have one or more members working abroad.

As the survey was conducted in Moldova, we approach our research question from the receiving household's perspective. In particular, our research examines the socio-economic circumstances of the household in the home country as well as migrant characteristics and home country specific variables which influence the incidence and amount of remittances

\footnotetext{
${ }^{1}$ The total population of the country is around 3.6 million in 2009.
} 
received by such households. We use these factors to interpret the main determinants for these transfers.

Our results show that differences in remittances across migrant-sending households in Moldova can be explained by a combination of household and migrant observed characteristics and community level variables. We also find that the function underlying the incidence and the level of remittances received is not always the same. For instance, we find that education has a positive impact on the probability to remit but not on the level of remittances. An important element of migration from Moldova is that most of it is temporary (or circular) in nature, and this form of migration is primarily to Russia. In order, therefore, to analyse these aspects more specifically, we also run separate estimations for those who migrated to Russia and find that there is a strong altruistic motive for remittance transfers from workers in this country. Presence of network determines both the likelihood and the amount of transfers for migrant workers to Russia whereas in the aggregate model they only impact the level. Furthermore, intent to stay less than a year has an insignificant impact on the level of transfers for migrant workers to Russia while it significantly impacts the amount in the aggregate model.

The rest of the paper is organised as follows. In Section 2 we review the trends of labour migration in Moldova since 1991. Section 3 presents review of the literature, theoretical motivation and empirical approach adopted in the paper. Section 4 explains the data and provides sample description while the discussion of results is presented in Section 5. The last section concludes the paper.

\section{Labour Migration from Moldova}

\subsection{Background}

The collapse of the Soviet Union in 1990 and later the Russian financial crisis of 1998 have had significant detrimental effect on Moldova. Early 1990s saw an increase in migration flows as the restrictions on citizens' movement came to an end coupled with a significant increase in unemployment rate as the country moved from a centralised to the market economy. The economic conditions were further exacerbated after the Russian crisis such that the country's industrial and agricultural output plummeted by $25 \%$ and $20 \%$ respectively and its exports were reduced by almost half by 1998-1999. In addition to this, major 
expenditure cuts in 1998 and 1999 due to unsustainable government deficit and privatisation of the agricultural sector increased the unemployment rate even further which moved more population below the poverty line (a total of $80 \%$ by 1999 , see Fig 2 ). Together, these factors propelled significant migration from the country, making it a mass phenomenon. ${ }^{2}$ Fig 3 shows the migration rate over the period 1999 and 2008.

A direct and significant effect of higher migration rate was the increased flow of remittances into the country. Fig 4 depicts the level of remittances in Moldova which has been on the rise since 2000 and passed the $\$ 2$ billion mark in 2008. An interesting point to note here is that the level of remittances sent via formal banking channels has been increasing steadily. According to a report by CBS-AXA (2005), there has been a $12 \%$ increase in the share of migrant households with a bank account, highlighting the role of remittances in promoting financial sector development in the receiving country.

This increase in inflows had a twin effect on the economy. On the one hand it prevented further decline of the economy by reducing the government's dependence on conditionalitybased borrowing, while on the other hand it encouraged yet higher outward migration. So, while the country experienced a remarkable increase (more than 30\%) in real GDP and a significant decline in the poverty rate (which was reduced to half in a span of merely four years in the period 2000-2004), migrants now accounted for about $28 \%$ of the working population and about $18 \%$ of the total population of Moldova in 2005.

\subsection{Characteristics of Labour Migration}

Labour migration from Moldova is broadly directed towards two regions: CIS countries, (predominantly Russia but to a small extent Ukraine as well) and Western Europe, particular to Italy. In addition to this, there is also considerable migration to Israel, Turkey and Romania. We find that the determinants of migration as well as the characteristics of migrants drawn to these regions differ significantly.

The results of the survey show that unemployment was the leading reason for Moldovans to leave the country, particularly for those who migrated to Russia (40\%), compared to those who migrated to the EU (26\%) or other countries (33\%). However, better quality of life and existence of job guarantee in the host country played an important role for those who moved

\footnotetext{
${ }^{2}$ According to Dujisin (2006) some villages lost up to 40 percent of their active population. The sight of villages with only children and elderly became increasingly common in the independent Moldovan state.
} 
to the EU, and 'good working conditions' were also cited as a key reason to choose Western Europe as a destination. Moreover, the poverty incidence among households with migrants in CIS countries is almost double (25\%) compared to households with migrants in the EU (13\%) or other countries $(21 \%)$. Taken collectively, this suggests that push factors appear to be relatively more important for households with migrants to CIS countries, whereas pull factors matter more for migrants to the EU and other countries.

As mentioned before, similar dichotomy exists between CIS and other countries in terms of the socio-economic characteristics of migrants to these countries. It is found that migrants to CIS countries are predominantly male, from rural areas with relatively low levels of education. This pattern closely correlates to the characteristics of jobs performed by migrants in these countries. More than $65 \%$ of migrants to Russia are employed in the construction industry, thus the apparent predominance of low-skilled men migrating to this region. Migrants to the CIS who work in sectors other than the construction industry also come from rural areas but their education levels are slightly higher. By contrast, migrants to the EU are mostly urban females with relatively higher level of qualifications.

The type of job coupled with the legal status in the destination country is a key determinant of the length of the migrant's stay abroad. Additionally, the motivation to migrate (i.e., economic need or opportunity) also plays an important role. According to Lucke et al (2007), if migration is needs driven, the migrant will return to his home country as soon as he earns/saves the desired additional income, which means this kind of migration by definition is temporary/seasonal in nature. Russia seems to be the destination of choice for temporary migrants, as the construction industry in the country depends on temporary contract work. In addition, migration to Russia is less costly due to both the geographic proximity as well as visa-free travel, making achieving target savings in a relatively short-time more plausible. On the other hand, migration to the EU is more long-term/permanent in nature, which is possibly driven by the difficulty in leaving the region once there as the initial entry is mostly illegal in nature.

In terms of remittances, the average amount sent by migrants also varies with the destination country. The survey results show that remittances sent by those who migrated to the EU were $\$ 1,749$ during the 12-month period preceding the survey, compared to $\$ 1,110$ and $\$ 1,130$ by migrants to the CIS and non-CIS/non-EU countries respectively. However, an analysis of the 
percentage of earning repatriated indicated that migrants to CIS nations tend to remit a larger share compared to migrants to the EU. This result relates to the key aspect of this paper, that temporary migrants' behave differently from those who migrate for long-term or permanently, though of course the cost of living in the host country also plays a part.

\section{Analytical Framework}

\subsection{Theory and Previous Literature}

Lucas and Stark (1985), in their seminal paper, initiated the current debate on the motivations to remit. Their work draws from the framework of New Economics of Labour Migration (NELM), an approach which views migration as a household decision where remittances are part of a strategy aimed at diversifying the resources of the household with a view to compensate for the risks linked to the absence of efficient insurance markets in home country (Cassarino 2004). Based on this, Lucas and Stark argue that there are three broad motivations to remit, namely: pure altruism, pure self-interest, and a combination of the two extremes tempered altruism or enlightened self-interest. Any kind of contract between the migrant and his family can be a part of the latter category, for example, insurance, exchange etc.

The theory of altruism posits that the migrant derives a positive utility from the well-being or consumption level of the family left behind (Becker 1974; Stark 1991). Based on this, the altruistic model predicts a positive relationship between the immigrant's earnings and the adverse conditions of the receiving household and an inverse relationship with the recipient household's income (Funkhouser 1995). The exchange motive, on the other hand, involves a contractual agreement between the migrant and the remittance-receiving household. Under this motive, remittances represent payments to the household at home for the services provided by them e.g. childcare, managing migrant's assets or handling other financial arrangements (Cox 1987).

The altruism and exchange motives in particular, but others as well, to be discussed below, could be captured by representing the migrant's utility function as follows (see Cox and Frank 1992):

$U_{m}=U\left(C_{m}, s, V\left[U_{h}\left(C_{h}, s\right)\right]\right)$ 
where, $U_{m}^{\prime}>0, U_{h}^{\prime}>0, U_{m}^{\prime \prime}>0$, and $U_{h}^{\prime \prime}<0$.Equation (1) represents the utility of the migrant which is a function of the migrant's own consumption $\left(C_{m}\right)$ and the consumption of the household $\left(C_{h}\right)$. It is assumed that the household in the source country provides services, $s$, to the migrant who derives positive utility from it. $\mathrm{V}$ is the felicity that the migrant derives from the household's consumption such that $\frac{\partial U_{m}}{\partial V}>0$.Under this setup migrant maximises utility subject to the constraints: $C_{m}=Y_{m}-R$ and $C_{h}=Y_{h}+R$, where $Y_{m}$ and $Y_{h}$ are the migrant's and household's pre-transfer income and $R$ is the amount of monetary transfers. Maximising the migrant's utility with respect to transfers gives us the optimal level of remittances. The key comparative static results that this generates are $\frac{\partial R}{\partial Y_{m}}>0$ and $\frac{\partial R}{\partial Y_{h}}>0$ or $\frac{\partial R}{\partial Y_{h}}<0$. The important implication is that the probability that a transfer occurs is positively related to $Y_{m}$. However, a change in household income could have opposing effects on the level of remittances sent. Within an altruistic structure, lower household income in the home country is associated with higher remittances in order to maintain the same level of household consumption, i.e., $\frac{\partial R}{\partial Y_{h}}<0$. However, if the transfers represent payments for services rendered by the household to the migrant, then we get a positive relationship, i.e., $\frac{\partial R}{\partial Y_{h}}>0$.

This can be explained as follows. If remittances represent payment for services rendered by the migrant from the household, the amount of transfers (R) sent can be written as $R=p . s$, where $p$ is the price of services and the effect of an increase in the income of the household on transfers can then be written as:

$$
\frac{\partial R}{\partial Y_{h}}=\frac{\partial p}{\partial Y_{h}} *_{S}
$$

With a fixed $s$, the implicit price of services will rise with $Y_{h}$ since an increase in $Y_{h}$ is likely to increase the supply price of services rendered by the household such that $\frac{\partial p}{\partial Y_{h}}>0$, thereby generating a prediction in stark contrast to that of the altruistic model.

Cox (1987) and Cox and Rank (1992), using inter-vivo transfer data from the US, find a positive relationship between the level of transfers and the recipient household's pre-transfer 
income, thus rejecting the altruistic hypothesis. Secondi (1997), using data for China, also finds that altruism alone cannot explain the transfers, and it is highly likely that exchange may be involved. A major obstacle in testing altruism is to separate it from alternative motivations to remit. So, what would seem as an altruistic behaviour on the part of migrants might simply be enlightened self-interest or some kind of contractual agreement between the migrant and the household. Therefore, other variables such as marital status, duration of stay in the host country and household size, which could all be linked to $s$ in eq. (1) above, have been used to test for the altruistic motive. The marital status of the migrant is used as an indicator of the degree of attachment of the migrant to the household. Marital relationship of the migrant to the household member in the home country is likely to have a positive impact on the likelihood as well as the amount of remittances, which will be associated with a higher value of $s$ in eq (1). A number of studies (e.g., Durand et al 1996, Holst and Scrooten, 2006; Merkle and Zimmerman, 1992) find a positive effect of marital status on remittances.

Duration of stay is generally linked to the remittance-decay hypothesis, i.e., the longer the period of residence in the host country the lower the incidence of remittances, though for those who intend to return home eventually could be likely to remit more towards investments in assets, real estate and social capital. Lowell and de la Garza (2000) show that for every $1 \%$ increase in time spent by immigrants in the Unites States the likelihood of remitting decreases by $2 \%$ whereas Glystos $(1997,1998)$ found that Greek immigrants to Germany remitted larger amounts (due to return illusion) than immigrants to Australia and United States. Aggarwal and Horowitz (2002), Osaki (2003) and Pleitez- Chavez (2004) find no evidence in favour of the existence of such relationship. It is thus interesting to explore the role of return migration, which is the most prominent form in Moldova, on the remittance behaviour of migrants to ascertain which determinants dominate when return intentions are realised most of the time.

One other aspect of remittances is insurance. The insurance model draws its rationale from the New Economics of Labour Migration (NELM), according to which the migration of a household member is a coping mechanism adopted by households to overcome market failures in the source country (for example poorly developed financial institutions) and insure themselves by spreading risks across countries. In effect, such households strategically locate family members in different places such that their incomes are uncorrelated. By doing so, they are able to spatially diversify their portfolio of labour resources, thereby minimising 
their overall exposure to income shock in any one place. Remittances in this case represent intra-family insurance payments against variations in incomes experienced by family members, such that their consumption levels remain smooth over time (in good and bad times). NELM is the sole economic theory that links the motive to remit to the decision to migrate. Thus the insurance model predicts that migrants who face greater risks and uncertainties in the destination countries are likely to remit larger sums back home to either 'purchase insurance' through family members or self-insure through the accumulation of precautionary savings (see Amuedo-Dorantes and Pozo, 2006; Piracha and Zhu, 2007).

Aggarwal and Horowitz (2002) analysed the effect of other migrants in the household to distinguish between insurance or other self-interest motives and altruism. The authors argue that under the insurance or other self-interest motives, the number of migrants in the household should not affect the amount of per-migrant remittances. However under altruism, the presence of other migrants will reduce the average size of remittances, as then, the first migrant is not solely responsible for the well being of the household. Hoddinott (1994) and Pleitez-Chavez (2004) find a positive impact of other migrant members on the probability of receiving remittances and an insignicant effect on the size of remittances. This is consistent with the self-interest and exchange theory of remitting whereby the presence of other members increases the probability that the migrant sends money and that any contract the migrant engages in with the household should not depend on the activity of other members of the household. On the other hand, Aggarwal and Horowitz (2002) find support for the presence of altruism. They find a negative relationship between the number of migrants in the household and the probability and the amount of remittances in Guyana. Similarly Naufal (2008), shows that the amount of remittances sent by Nicaraguan migrants decreases as the number of migrants from the household increases.

The investment motive for sending remittances has been tested by including community level variables such as presence of banks, the presence of employment and business opportunities in the home country. Durand et al (1996) and Sana and Massey (2005) were the first ones to adopt this approach. The authors confirm that the more economically dynamic the market in the home country, the greater is the likelihood that the migrant remits. This clearly suggests that remittances are sent as investment under the right conditions.

\subsection{Empirical Specification}


The reduced form expression for the latent variable determining participation in remittance behaviour can be expressed as:

$R^{*}=R\left(X_{m}, Y_{h}, Y_{m}, E_{h}, C\right)$

where $X_{m}$ are the human capital variables (migrant's age, gender, education level), $Y_{h}$ and $Y_{m}$ are household and migrant income, $E_{h}$ is a vector of household characteristics and C captures the community variables. Transfers between the migrant and the household are also determined by the degree of development of capital markets - underdeveloped capital markets in the home country could have a positive effect on the remittance transfers to help alleviate borrowing constraints of the household, but it can also have a negative relationship if the main motive is investment which means potentially limited investment options. To capture these aspects, we include household characteristics and community variables into our specification.

When modelling remittance function, for a given population, a substantial part of the population could be observed with zero remittances. In the literature such zero remittances are identified as either behavioural zeros or random zeros. Behavioural zero's represent a conscious choice arising from the comparison between the utility of sending versus not sending remittances (Mahuteau et al. 2010). On the other hand, random zeros, also called potential positive (Moffat, 2005), imply that the migrant might want to send remittances or have a preference towards remitting, but is not able to do so for some reason related to personal circumstances. This implies that remittances are a mixture of discrete (to generate zero observations) and continuous (to generate positive observations) distributions. Under such circumstances, application of Ordinary Least Squares (OLS) to a remittance function would give biased and inconsistent estimates, as it fails to account for the qualitative differences between censored (zero) and uncensored (continuous) observations.

Two alternative models have been put forward to account for the combined nature of the distribution of remittances. The first model uses a parametric approach and is based on strong assumptions about the conditional data distribution and the functional form. The second model maintains the assumptions about functional form but partially relaxes the distributional assumptions (Cameron and Trivedi, 2005). 
The former and most common way of dealing with censored dependent variable is to estimate a Tobit Model. We use a linear functional form for equation (2):

$R^{*}=\alpha+\gamma_{1} X+\gamma_{2} E+\gamma_{3} C+\mu$

where $X$ is a vector of all migrant characteristics including his income, $E$ captures household characteristics including household income, $C$ represents community variables and $\mu$ is a normally distributed error term.

However, the main drawback of the Tobit model is that it makes a strong assumption that the same probability function generates both the zeros and the positive values. In other words, it assumes the decision to remit and the level of participation as stemming from the same probability mechanism, which makes it an inappropriate model for our analysis and therefore will not be presented in detail here. ${ }^{3}$

The second model employed for censored dependent variable is more flexible and allows for the possibility to specify different models for the censoring and the outcome components. The advantage of these models is that common regressors of both equations may affect the two decisions differently. ${ }^{4}$ Moreover, this class of models also allows us to condition the participation decision on a different set of regressors than used to explain the level of remittances (Mahuteau et al. 2010).

There are two variants of this class of models, depending on whether we interpret part of the non-remittances as coming from some random event that prevented the migrant from remitting despite being willing to do so (two-part, selection model) or whether we treat the zeros as stemming from an individual's decision not to participate (double hurdle model).

Both models use two equations (which can either be estimated simultaneously or not) - one for the participation decision and the other for the level of remittances. These decisions (in most cases) are recorded by two questions, where the first question records participation while the second records the level. Based on these questions, we expect that only those

\footnotetext{
${ }^{3}$ The results from the model are presented in the Appendix.

${ }^{4}$ There is a debate in the literature concerning the probability mechanism that generates the zero and the positives. Bannerjee (1984) suggests that the zero and the positives are generated by the same mechanism while Funkhouser (1995) and Masssey and Basem (1992) argue the opposite.
} 
individuals who answer the first question in the affirmative should have positive values (greater than zero) for the second question. However, in such studies, it is common to encounter individuals who answer the first question in the affirmative, but for the subsequent question record no amount, i.e. individuals who report that they receive remittances but in the amount question report zero. Such zeros can be categorised as either behavioural zeros (nonparticipation) or random zeros (participation but no remittances). Double-hurdle models are specifically designed to deal with these two-types of zero, while two-part and selection models assume that once the first hurdle is overcome (participation) one should not observe any zeros.

In this paper, the occurrence and the level of remittances variables are constructed from two separate questions but we only observe one type of zero i.e., only those who do not receive remittances report zeros for the level question. ${ }^{5}$ Since we do not observe participation and zero remittances simultaneously, double hurdle model will not improve our estimations in any way. Given this, we will limit our estimation to the two-part and selection models.

The two-part model specifies one model for the censoring mechanism and a second distinct model for the outcome, conditional on the outcome being observed. Thus, it allows for a different data generation process for the two parts. However, it does not account for the possibility that those with positive levels of expenditure are not randomly selected from the population, thereby raising selection issues. On the other hand, the selection model, corrects this bias by allowing for possible dependence in the two-parts of the model. In what follows, we will discuss the structure of the two models.

The two-part model has three constituents - the observed outcome, participation equation and level equation. These can be represented as below:

Observed Outcome:

$$
R=d R^{*}
$$

$d=1$ for participants and 0 for non-participants and $\mathrm{R}^{* *}$ is given in eq (6) below

Participation Equation: $Z=\gamma W+v$

\footnotetext{
${ }^{5}$ Once again, note that our analysis is based on the data collected in Moldova, i.e., from the recipients point of view. We therefore use remittance receipts to interpret the determinants of remittance behaviour.
} 
$d=1$ if $Z>0,0$ otherwise.

Level Equation: $R^{* *}=\max \left[0, R^{*}\right]$ and $R^{*}=\beta Y+\mu$

$W$ and $Y$ are the regressors affecting the participation and level equation respectively and $u$ and $v$ are the disturbance terms, which are randomly distributed with bivariate normal distribution. The regressors that appear are mostly same in both parts of the model, however this can be relaxed if there are any obvious exclusion restrictions.

Thus, the first part of the two-part model is a binary outcome equation that model the $\operatorname{Pr}(R>0)$ and is estimated by either a logit or a probit, while the second part uses a linear regression to model $E(R \mid R>0)$. As the two parts are independent, the joint likelihood for the two-part is the sum of the two log likelihoods.

On the other hand, the Heckman sample selection model introduces a second latent variable $Z_{i}^{*}$ to take account of the selection effects. The model can be specified in the following equations:

$$
\begin{aligned}
& \begin{array}{l}
Z^{*}=\gamma W+v \text {, where } v \approx N(0,1) \\
Z=Z^{*} \text { if } \gamma w+v>0
\end{array} \\
& Z=0 \text { if } \gamma w+v \leq 0 \\
& R=\beta Y+\mu \text { if } Z^{*}>0 \text { where } \mu \approx N\left(0, \sigma^{2}\right) \\
& R=0 \text { if } Z^{*} \leq 0
\end{aligned}
$$

Equations 7 and 8 are the participation and level equations respectively, with $\gamma$ and $\beta$ as the parameter vectors to be estimated. Additionally we assume that the unobservables in both equations (participation and level equation) have a bivariate distribution with correlation $\rho$.

Similar to the two-part model, the selection model also involves estimating the participation decision using probit. From this we can calculate the Mill's ratio. This ratio is then used as an additional regressor in the level equation which is estimated using OLS. The rationale for including the Mill's ratio as an additional regressor in the second step is to correct for any bias that might be present due to the selectivity issues.

There are both theoretical and empirical arguments that could be used in making the appropriate choice between the two approaches (see Dow and Norton, 2003). The theoretical 
issue involves determining whether the aim is to model actual or potential outcome. The sample-selection model is better suited for the potential outcomes while the two-part model is better for the actual outcome. In our case it is clear that we are trying to model actual outcome rather than potential outcome.

The empirical issue concerns identifying whether there are any valid exclusion restrictions, without which the sample selection model may underperform. In case of the sample selection model, identification is achieved through the use of an exclusion restriction, i.e., when at least one 'extra' explanatory variable influences the participation but not the subsequent outcome of interest. In the absence of any such restriction the alternative potential source of identification is the functional form or, in other words, it depends on the non-linearity of the inverse mills ratio (the extra term) that appears in the level equation. However, critics have argued that the inverse mills ratio is frequently an approximately linear function over a wide range of its argument and therefore the estimates from the level equation in the sample selection model may be non-robust owing to collinearity issues. We estimate the selection model by using three variables as exclusion restrictions in the participation equation, namely, number of migrants in the household, migrant gender and if migrant is the main earner of the household. The theoretical argument behind the utilisation of these variables is as follows: if the household has more than one migrant abroad then some of them would not be expected to remit, or perhaps not regularly. Previous literature has identified that female migrants are more likely to remit out of altruistic feelings (Lowell and Orozco 2006); however the amount depends on their income. Similarly, if the migrant is the main earner of the household he is more likely to remit, although the amount sent will again depend on their income. Thus, all three variables will help determine the likelihood of remitting yet not the amount of remittances.

So, altogether we carry out three types of estimations: The basic Tobit model, the two-part model and the selection model. The dependent variables are probability of receiving remittances and amount of remittances received by the household in the last twelve months. Remittance incidence is equal to 1 if the household is observed to have received remittances from abroad, and zero otherwise. Remittance amounts are assumed to be personal transfers from overseas family members and ex-family members. 


\section{Data and Sample Description}

We use CBS-AXA data drawn from a survey conducted by Swedish International Development Agency (SIDA) and International Organisation for Migration between June and August 2006. It is an extensive household level data set that provides a detailed analysis of migration and remittances in Moldova. It complements migration data available from the quarterly Labour Force Survey (LFS) (carried out by the National Bureau of Statistics) and the Balance of Payments information on remittances provided by the National Bank of Moldova (NBM).

One important purpose of the CBS-AXA survey was to compare household with migrants to those without. Therefore the survey is designed to be representative of all Moldovan households. It implements a multi-stage sampling design and contains information of 14,068 individuals in 3,940 households, including 4,481 (31.85\%) with migration experience. Out of this $25 \%$ of the households report as having at least one current or ex-household member ${ }^{6}$ currently working abroad while $30 \%$ of the total households report that they had received remittances in the 12 months prior to the survey interview date.

The survey methodology involved interviewing one member of the household who was asked to supply the information about household perceived wealth status, household size, ownership of assets etc, as well as about the details (age, gender, marital status, education, labour market experience) of all household members, including those living abroad. In 95\% of the cases, the head of the household answered the questionnaire. For those who have a migrant (current or past) in the household, detailed information about the year of migration, problems and costs associated with migration process, living and working conditions and legal status in the destination country, future intentions, frequency and amount of money or goods sent home by the migrant, the effect of remittances on household welfare and the use of remittances are also recorded.

Our estimates of remittance behaviour are based on the following two questions asked in the survey.

Do you receive monetary remittances from abroad?

\footnotetext{
${ }^{6}$ Ex-household members are those working-age migrants who are no longer a part of the household in Moldova, and may have since formed their own household abroad.
} 
If the respondent answered yes, he or she is asked the next question:

How much money did you receive from your family/relatives/ex-members of family in the last 12 months?

In the survey remittances are measured at the household level, though some explanatory variables are reported at the individual level. We do not use measures of individual characteristics for all household members, but only for the head of the household and the migrant member of the household. In our analysis we include a vector of household characteristics representing the structure and the net earnings capacity of the migrant's household in the origin country, a vector of migrant individual characteristics and community variables.

Household characteristics include measures of the age and gender of the household head, perceived income status of the household prior to the first migrant leaving the household, wealth status of the household, number of dependents in the house (below fifteen), presence of other migrant members in the household and location of the household.

Information on perceived income status was gathered from the head of household's response on whether the financial status of the household is very good, good, satisfactory, bad or very bad to buy bare necessities. As some of the cell sizes were very small, two broad categories were formed, high income (if very good and good) and low income (satisfactory, bad and very $\mathrm{bad}$ ). Although the use of such subjective measures is becoming increasingly popular in economics, it is important to bear in mind the biases that may be involved. Firstly, subjective assessment of income may be driven by 'cognitive problems' such as ordering of questions, wording, scales etc. Secondly, there might also be the case of a 'response bias', as people might be embarrassed to report their true income situation. Thirdly, according to Bertrand and Mullainathan (2001), 'cognitive dissonance' might occur, which means that people have a tendency to report an income level which corresponds to their past income standard. Finally, people assess their living standards from a comparative viewpoint, implying their response might be dependent on the conditions in the neighbourhood or that of their friends and relatives.

With this in mind, we complement our income variable by constructing a wealth index of the household. Wealth is a more stable indicator than income and can have a considerable impact 
on migration and the consequent receipt of remittances. A household was considered wealthy if it owned an apartment/ land, vehicle and more than four of the listed durables. ${ }^{7}$

The individual migrant characteristics capture the migrant's age, gender, education level, intent of duration of stay at destination country and whether the migrant is the head and the main earner of the household. We also include two community variables to inform us about the theory of investment motive (discussed in the previous section). The first variable is a cumulative measure of the trust in different financial institutions (FI), which include banks, micro-financial agencies, saving associations and post offices. ${ }^{8}$ This variable is expected to be a proxy for an efficient economic environment in the country which is likely to have a positive impact on remittance flows. The second is a dummy variable to capture network effects, equal to one if the household has social contacts in the host country and zero otherwise.

The survey questionnaire is answered by an adult member (between the ages of 18 and 65) of the household. ${ }^{9}$ We impose certain restriction on our sample. First, in the absence of the head of the household, i.e., when he is a 'current migrant', we assume the 'second' member of the household, who is answering the questionnaire, to be the decision maker, i.e., in terms of receipt and use of remittances etc. Second, in order to avoid the potential endogeneity associated with the perceived household income, we have dropped those households in which migration (by any member) was experienced before 1997. We instead make use of the household's perceived income status prior to the first migrant leaving the household, which gives us the economic position of the household at the time the decision to migrate was being taken. Following these restrictions, our sample consists of 747 migrant households (those who have migrants working or living abroad in either 2005 or during the first half of 2006) with more than half (59\%) reporting that they had received remittances within the 12-month period prior to the survey interview date.

Column 1 of Table 1 reports data for remittance receiving households and column 2 reports data for households not receiving remittances. As can be seen, in the case of migrant characteristics, migrants who send remittances tend to be slightly older and more educated

\footnotetext{
${ }^{7}$ Washing machine, microwave oven, television, cable television, TV satellite dish, home telephone, mobile phone, computer and gas.

${ }^{8}$ If the person responded that he trusted more than two financial institutions then that household was labelled as having trust in the institutions of the home country.

${ }^{9}$ About $95 \%$ of the cases it was the head of the household
} 
than those who do not. They are also more likely to be females from an urban area. Furthermore, $52 \%$ of migrants from remittance receiving households are the household heads. The other major differences between the two groups are in terms of the community variables with $53 \%$ of the remittance-receiving households reporting that they trust the financial institutions of the country compared to only $34 \%$ of those who do not receive remittances. Moreover such households are more likely to know people in the host country $(81 \%$ versus $73 \%)$.

\section{Results and Discussion}

We find that the log likelihood for the Tobit model (Table A1) is much lower than that of the two-part model and the selection model, implying that the latter models fit the data considerably better. In addition, the selection model (Table 2) fails the likelihood ratio test even though the results are rather similar to those of the two-part model. The $\rho$ value of 0.64 implies that the errors of the two equations are not correlated and the hypothesis that the two parts are independent cannot be rejected and, thus, the results of the level equation of the two part model are not biased. This suggests that the two-part model is more appropriate in explaining the remittance behaviour in Moldova. ${ }^{10}$ In addition to providing a better fit to our data it also provides greater flexibility by allowing the covariates to differently impact the two parts of the model. We will therefore limit our discussion to the two-part model.

Table 2 provides the estimates for the participation equation and the level equation of the two-part model and the Heckman selection model respectively. The model was estimated for the whole sample, conditional on a set of exogenous variables, to determine the probability of receiving remittances using a dummy variable for receipt (rem=1 if household received remittances and 0 otherwise, which is $d$ in the model discussed in section 3.2). Column 1 presents the estimates for the participation equation while column 2 shows the continuous choice of the amount of remittances received (for those households that received remittances).

\footnotetext{
${ }^{10}$ Other studies using the Heckman section model such as Funkhouser (1995) and Massey and Basem (1992) have also found no significant selection effects.
} 


\subsection{The Participation Equation}

Analysing column 1 of Table 2, we observe that in comparison to males, female migrants are more likely to remit. Majority of the females from Moldova migrate to the EU, where the wages are relatively higher, hence they have a higher propensity to remit. Moreover, we find that households with temporary or short-term migrants are less likely to receive remittances.

Furthermore, the variable capturing the strength of ties between the migrant and the household is of the predicted sign and in accordance with our hypothesis. We find that households where the migrant is the main earner are $11 \%$ more likely to receive remittances than their counterparts. This finding lends supports to the idea that being the primary earner of the household plays an important role in the remittance process.

On the household side, we find that the income of the household has a negative impact on the likelihood of remittances. This is consistent with the altruistic motive wherein higher the household income, lower are the remittances. Furthermore, the wealth status of the household fails to register any statistical significance, although its sign is consistent with the predictions of the altruistic model too. In addition, the variable capturing the presence of other migrant members provides additional support for the altruistic hypothesis. Consistent with the discussion in section 3, we find that probability of remitting decreases with the presence of other migrant members in the household.

Both community variables (NELM and presence of networks in the host country) are strong determinants of the likelihood of receiving remittances by households. The NELM variable that captures the household's trust in the financial institutions in the home country increases the incidence of remittances by $20 \%$. Trust in the financial institutions is an indication of the local community's economic climate and an important factor in determining if a favourable return on investment can be made or not. Durand et al (1996) find that migrants are not only more likely to remit, but remit more to economically dynamic communities. Thus, a significant effect of this variable lends support to the idea that remittances are sent by migrants as investment under the right conditions.

In stark contrast to Amuedo-Dorantes and Pozo's (2006) findings, but in agreement with the argument by Carling (2008), we find that those with networks at the destination country are $7.5 \%$ more likely to remit than those without one. Networks in the destination country help 
lower assimilation costs and increase transnational ties with the home country, which together have a positive impact on the likelihood of remitting. We can also explain this using Dasgupta's (1993) concept of 'altruistic cultural norms', which posits that the presence of contacts in the host country generates positive externalities. Moreover, the existence of coethnic networks enforce 'altruistic cultural norms', such as responsibility/duty norm, according to which a migrant's duty is to send part of his income to his household in the origin country. These norms can be enforced by the geographical proximity of co-ethnics and have a positive impact on the probability of remitting as well as the amount of remittances sent. In other words these norms serve as a reinforcing factor, which encourages remittances. The positive effect on remittance incidence is however in contrast to the predicted effect of the insurance model according to which a reduction in risks should reduce a migrant's insurance motivation to remit ${ }^{11}$.

Thus, with regard to the probability to receive remittances, the results from the two-part model suggest that the variation in remittance flows in Moldova can be explained by differences in income of the household, the kinship ties between the household in the home country, migrants age, gender, his intended duration of stay and presence of networks in the host country and economic development of the home country (proxied by the households' trust in its financial institutions). From these factors, we can deduce that it is mainly altruism and investment that motivates the flows from migrants to their home country.

\subsection{The Level Equation}

From Table 2 we can see that a few determinants affect the probability to receive remittances in one way and the level of remittances in the opposite way. This clearly implies that in case of Moldova the two dimensions of remitting- incidence and level of remittances are independent.

It is interesting to note that although the education level of the migrant had an insignificant impact on the incidence of remittances; it is an important determinant of the level of remittances. Each additional year of education increases the amount of remittances by $15 \%$. As noted in section 4, migrant's earning is proxied by his education level, i.e., the more

\footnotetext{
${ }^{11}$ The presence of networks helps the migrant to settle in smoothly in the host country and reduces the various costs (settlement costs, job-search costs, and period of job-search) and hence risks in the host country. As a result the migrant is able to save more and hence remit more.
} 
educated the migrant, higher will be his income. Thus the positive coefficient on the variable confirms the first prediction and also appears to be consistent with the altruism motive discussed in section 3. The education level of the migrant also captures the loan repayment motive. It is likely that the cost of education of such migrants has been borne by the family in the source country. Hence, remittances by such migrants can be considered as repayments for the initial investment made by the migrant's family towards his education.

Along the same lines, the presence of dependent members in the household has a significantly positive impact on the amount of remittances received by the household increasing by $20 \%$ with each additional dependent member in the family. Comparing the impact across the incidence and the amount of remittances sent by the migrant, we see that each additional dependent member in the family at home increases the amount of remittances sent by the migrant by ten times more than it affects its probability. This suggests that the needs of the family at home are quite important to migrants and is also consistent with the discussion in section 2 according to which the majority of migration from Moldova is needsdriven.

Moreover, the age of the household head as well as the community variables positively affect the amount of remittances received. Specifically, we find that migrants with networks in the host country are not only more likely to remit but send 30\% more than their counterparts. Also, households who trust the financial institutions of Moldova receive $40 \%$ more transfers.

\subsection{Extensions and Sensitivity Analysis}

A potential bias could affect the results presented in Table 2, due to unobserved heterogeneity that may stem from omitted unobservable factors that influence both the decision to migrate as well as remittance behaviour. For this reason, we supplement our findings by using the rate of migration as an additional regressor.

We make use of variable that captures the rate of migration in Moldova. We gather information on this from the quarterly Labour Force Survey (LFS) conducted by the National Bureau of Statistics and use it for the current analysis. The variable highlights the migration prevalence in the different districts of Moldova. The LFS defines migration prevalence as the number of migrants per 100 residents, between the ages of 18 and 64 and classifies them into 
three broad categories - high, medium and low migration prevalence. Thus, a district with high migration prevalence is one which has more than 25 migrants per 100 residents. Similarly, districts with 10-25 migrants and less than 10 migrants (per 100 residents) are labelled, respectively, as medium and low migration prevalence districts. However, given the classification, we find that some of the cell sizes were quite small, hence we combine them to form two broad categories: low and high migration prevalence areas. Those households, which reside in districts with less than 10 migrants per 100 residents, are part of the first category and the rest belong to the second category ${ }^{12}$.

The rate of migration is likely to have a positive impact on the remaining households' propensity to migrate as it lowers the costs and risks involved with it. Similarly, living in an area with high migration prevalence has a positive impact on the likelihood and the amount of remittances sent by the migrant, through the social networking effect. Using this variable, we re-estimate the models for the three groups separately.

In table 3, column 1 and 2 display the results of the pooled sample using the two-part model. Columns 3-6 present the results from the two-part model for areas with low and high migration rates respectively. Comparing columns 3 (4) and 5 (6), the most noticeable difference is the impact of networks in the destination country on remittance behaviour. We can see that for areas with low prevalence of migration, existence of networks in the host country has an insignificant effect on remittances. As not many people from this region move abroad, it is reasonable to assume that households in this area do not know many people in the host country too, hence the insignificant impact. In stark contrast, for high migration areas, the presence of networks in the host country matters significantly. This result seems quite plausible since networking increases the probability to migrate and has a positive impact on the consequent remittances.

In addition to the above, we also estimate the two-part model by migration destinations. As the majority of migration from Moldova is to Russia, we classify the destination countries into two broad categories - Russia and other countries. About $60 \%$ of our sample belongs to the former group. Column 1 and 2 of table 4 present the results for Russia while columns 3 and 4 do the same for other destination countries. The most interesting result is the variables capturing the networks at the destination. We find that networks in Russia have a

12 The results do not change if instead we use 20 migrants per 100 residents. 
significantly positive impact both on the incidence and the level of remittances received compared to other countries where it is insignificant.

With respect to the household characteristics, presence of other migrants in the household has a significantly negative impact on the probability of remitting for households with migrants to Russia. Also, the presence of dependents below the age of 15 has a significantly positive impact on the amount of remittances. Both these results suggest that it is highly likely that transfers from migrants to Russia have an altruistic component to them.

We also find that the intended duration of stay of the migrant does not register any statistical significance for Russia. However, the variable is highly significant for migrants to other countries. As migration to Russia is mainly temporary by nature, the insignificance of the variable can be justified. For households with migrants to other countries, if the migrant is the main earner of the household it has a significantly positive impact on the incidence of remitting. However, this effect is insignificant for migrants to Russia.

\section{Concluding remarks}

The aim of the paper was to highlight the variables that determine the propensity to receive remittances and the amount of remittances by households in Moldova. We then used the results from this exercise to explore the likely motivations behind these transfers. In doing so, we made use of a large household survey data and analysed the migrant-sending households' propensity to receive remittances from abroad. Thus, our empirical model incorporated the determinants of remittances in terms of observed migrant and household characteristics that are assumed to capture the underlying motives of remitting suggested by existing theories of remittances. The analysis is aimed to help create migration schemes that affect the way remittances are channelled into different purposes and raise awareness about how different policies will lead to different incentives to remit.

We allowed the explanatory variables to differ across the two dimensions of remitting. Accordingly, we set up our remittance model both as a one-stage and two-stage specifications. We found that the two-part model fits our data better and thus seems the preferred choice to model remittance behaviour in Moldova. 
Our general findings are that the function underlying the incidence and the level of remittances received is not the same; a combination of household, observed migrant characteristics and community variables are key in explaining the remittances behaviour in Moldova; and remittances from migrants are primarily sent for either altruistic or investment reasons. In terms of policy relevance of remittances, the findings can help policymakers and governments to better understand and predict the effects of international remittances. For example, we find that remittances positively respond to the economic environment in the home country. Therefore, if the government wants to attract remittances, it should invest more in the financial infrastructure of the country such that people's confidence in the country's financial system increases which leads to a subsequent increase in the flow of remittances. According to Catrinescu et al (2009), the key to increasing the longer-term development impact of remittances is to implement economic and governance policies that support a sound business economic environment.

However, it is important to bear in mind that this outflow of human resource and the inflow of money have come at a high social cost to Moldova because of the following reasons. First, an increasing proportion of migrants are relatively high-skilled individuals who are attracted by the higher wages abroad. The move by this category of workers is more likely to be permanent, causing a major shortfall of skilled workers in the country. Second, the inflow of remittances has led to an increase in the prices of goods and services in the country which has adversely affected the non-migrant households and induced migration. Third, increased dependence on remittances has become a 'normal way' of life for many families in Moldova. The majority of these remittances are used for current expenses and only a small amount is invested. Finally, this pattern has led to an observed imbalance in the demographics of the country, as the young (economically active) and dynamic are the first to leave the country.

In the backdrop of this, we can say that although migration had increased welfare on both the microeconomic and the macroeconomic level, it has also fostered dependence. Therefore, it is important to recognise that even though for many developing countries, including Moldova, remittances are an important source of external financing than development aid or foreign direct investment; they cannot be treated as a universal solution to all developmental problems. Instead, what is required is for the government to create cohesive policies that view migration as an integral part of the development plan and help the nation to maximise benefits of international labour mobility and the associated inflow of remittances. It should be 
remembered that these transfers in the first place arise due to the failure of development across less-developed countries. In the words of Ratha (2003), 'although remittances can be leverages for the development of poor countries they should not be considered as a substitute for development at home'. 


\section{References}

Aggarwal, R., and A.W. Horowitz (2002). Are International Remittances Altruism or Insurance? Evidence from Guyana Using Multiple-migrant Households. World Development, 30(11), 2033-2044.

Amuedo-Dorantes, C. \& S. Pozo. 2006. Remittances as Insurance: Evidence from Mexican immigrants, Journal of Population Economics, 19:227-254.

Bauer, T.K. and M. Sinning (2005). Blinder-Oaxaca Decomposition for Tobit Models, Applied Economics, 42 (12), 1569-1575.

Becker, G. (1974). A Theory of Social Interactions. Journal of Political Economy, Vol. 82, 1063-1093.

Cameron, C.A and P.K. Trivedi (2005). Microeconometrics: Methods and Application. Cambridge University Press, NewYork.

Carling, J. (2008). The Determinants of Migrant Remittances. Oxford Review of Economic Policy, 24(3), 582-599.

Cassarino, J-P. (2004). Theorising Return Migration: A Conceptual Approach to Returnees Revisited. International Journal on Multicultural Societies. 6 (2).

Catrinescu, N., M. Leon-Ledesma, M. Piracha, B. Quillin (2009). Remittances, Institutions and Economic Growth. World Developemt, 38(8): 81-92.

Cox, D. (1987). Motives for Private Income Transfer. Journal of Political Economy, Vol. 95(3), 508-547.

Cox, D. And E. Jimenez (1990). Achieving Social Objectives Through Private Transfers. World Bank Research Observer, 14, 245-255.

Cox, D. and M. Rank (1992). Inter-vivo Transfers and Inter-generational Exchange. Review of Economics and Statistics, 74 (2),305-314.

Cuc, M., E. Lundback, and E. Ruggiero (2005). Migration and Remittances in Moldova. Washingtom, D.C.: International Monetary Fund.

Dasgupta, P. (1993). An Inquiry into Well-Being and Destitution. Oxford: Clarendon.

Dow, W.H. and E.C. Norton (2003). Choosing Between and Interpreting the Heckit and TwoPart Models for Corner Solutions. Health Services \& Outcomes Research Methodology 4(1):5-18.

Durand, J., W. Kandel, E.A. Parrado, and D.S. Massey (1996). International Migration and Development in Mexican Communities. Demography, 33(2), 249-264. 
Dustmann, C. and J. Mestres (2010). Remittances and Temporary Migration. Journal of Development Economics, 92(1), 62-70.

Funkhouser, E. (1995). Remittances from International Migration: A Comparison of E1 Salvador and Nicaragua. Review of Economics and Statistics, 77(1), 137.

Glystos N.P. (1988). Remittances in Temporary Migration: A Theoretical Model and its Testing with the Greek-German Experience. Weltwertschaftliches Archiv, 124(3), 409-435.

Glystos N.P. (1997). Determinants and Effects of Migrant Remittances: A Survey. International Migration: Trends Policies and Economic Impact. Routledge. London and New York.

Hagen-Zanker, J. and M. Siegal (2007). The Determinants of Remittances: A Review of Literature. Working Paper MGSoG/2007/WPOO3, Maastricht University, Maastricht Graduate School of Governance.

Hagen-Zanker, J. and M. Siegal (2009). A Critical Discussion of the Motivations to Remit in Albania and Moldova, Romanian Journal of European Studies, No.7-8.

Hoddinott, J., (1994). A Model of Migration and Remittances Applied to Western Kenya, Oxford Economic Papers, 46, 459-476.

Holst, E. and M. Schrooten (2006). Migration and Money- What Determines Remittances? Evidence from Germany. Discussion Paper Series A No.477, Institute of Economic Research, Hitotsubashi University. Japan.

Lucas, R.E. and O. Stark (1985). Motivations to Remit: Evidence from Botswana, Journal of Political Economy, Vol. 93,901-918.

Lowell, B. L. and R. De La Grazza (2000). The Developmental Role of Remittances in U.S. Latino Communities and in Latin American Countries. Washington, DC: Inter-American Dialogue \& Tomás Rivera Policy Institute.

Lowell, B.L. and M. Orozco (2006). Gender Specific Determinants of Remittances and Gender-Specific Remittance Mechanism. Report to the World Bank and Gender and Development Group.

Mahuteau, S., M. Piracha and M. Tani (2010). Selection Policy and Immigrant's Remittance Behaviour. IZA Discussion Paper No. 4874. Institute for the Study of Labor (IZA), Bonn.

Massey, D. S. and L. Basem (1992). Determinants of Savings, Remittances, and Spending Patterns among U.S. Migrants in Four Mexican Communities, Sociological Inquiry 62(2): 185-207.

McDonald, J.F. and R.A. Moffitt (1980). The Uses of Tobit Analysis, Review of Economics and Statistics, 62(2), 318-21. 
Merkle, L. and K. Zimmermann (1992): "Saving and Remittances: Guest Workers in West Germany", in Klaus Zimmermann (ed.), Migration and Economic Development, Berlin: Springer-Verlag, 55-75.

Osaki, K. (2003). Migrant Remittances in Thailand: Economic Necessity or Social Norm. Journal of Population Research, 20(2), 203-222.

Osili, U. K. (2007). Remittances and Savings from international Migration: Theory and evidence using a matched sample. Journal of Development Economics. Vol. 83(2),446-465.

Piracha, M. and Y. Zhu (2007). Precautionary Savings by Natives and Immigrants in Germany, IZA Discussion Paper No. 2942, Bonn, Germany.

Pleitez-Chavez, R.A (2004). Remittances as a Strategy to Cope with Systemic Risk: Panel Results from Rural Households in El Salvador. Unpublished PhD, Ohio State University, Columbus.

Rapoport H. and F. Docquier (2004). Economics of Migrant's Remittances. Working Paper No. 236. Stanford Centre for International Development, Stanford.

Ratha, D. (2003). Worker's Remittances: An Important and Stable Source of External Development Finance. In 'Global Development Finance: Striving for Stability in Development Finance, Volume I: Analysis and Statistical Appendix', pp 157-175, World Bank. Washington, D.C.

Sana, M., and D.S. Massey (2005). Household Composition, Family Migration, and Community Context: Migrant Remittances in Four Countries. Social Science Quarterly, $86(2), 509-528$.

Secondi, G. (1997). Private Monetary Transfers in Rural China: Are Families Altruistic? Journal of Development Studies. 33, 487-511.

Stark, O. (1991). The Migration of Labor, Oxford: Basil Blackwell.

The World Bank (2005). "Global Economic Prospects 2006: Economic Implications of Remittances and Migration", Washington, D.C.: International Bank for Reconstruction and Development/The World Bank.

Van de Ven, W. P. M. M. and B.M.S. van Praag (1981). The demand for Deductibles in Private Health Insurance: A Probit Model with Sample Selection, Journal of Econometrics, $17(2), 229-252$. 
Figure 1: Remittances as a percentage of GDP (2000-2008)

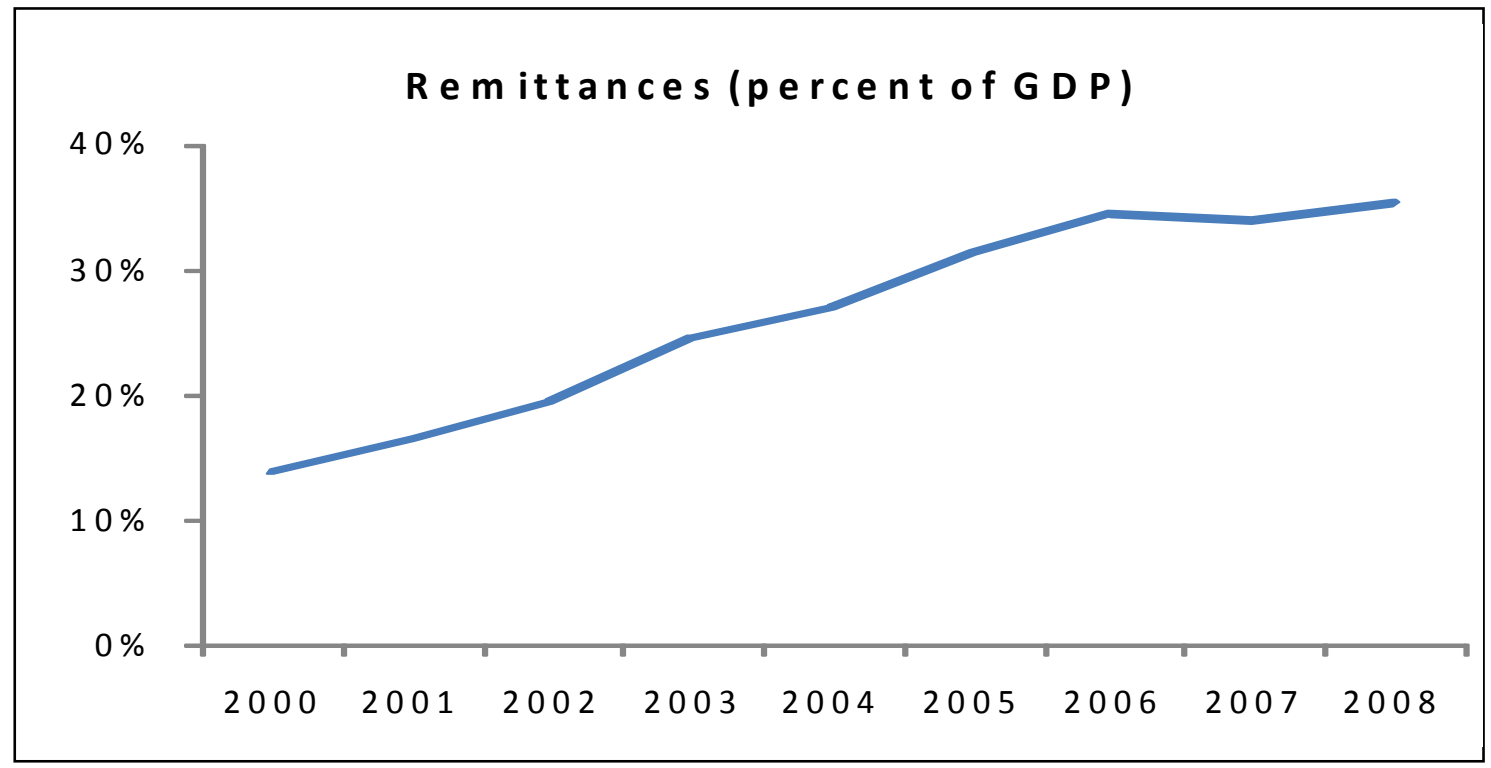

Figure 2: GDP Growth and Poverty Rate (1997-2005)

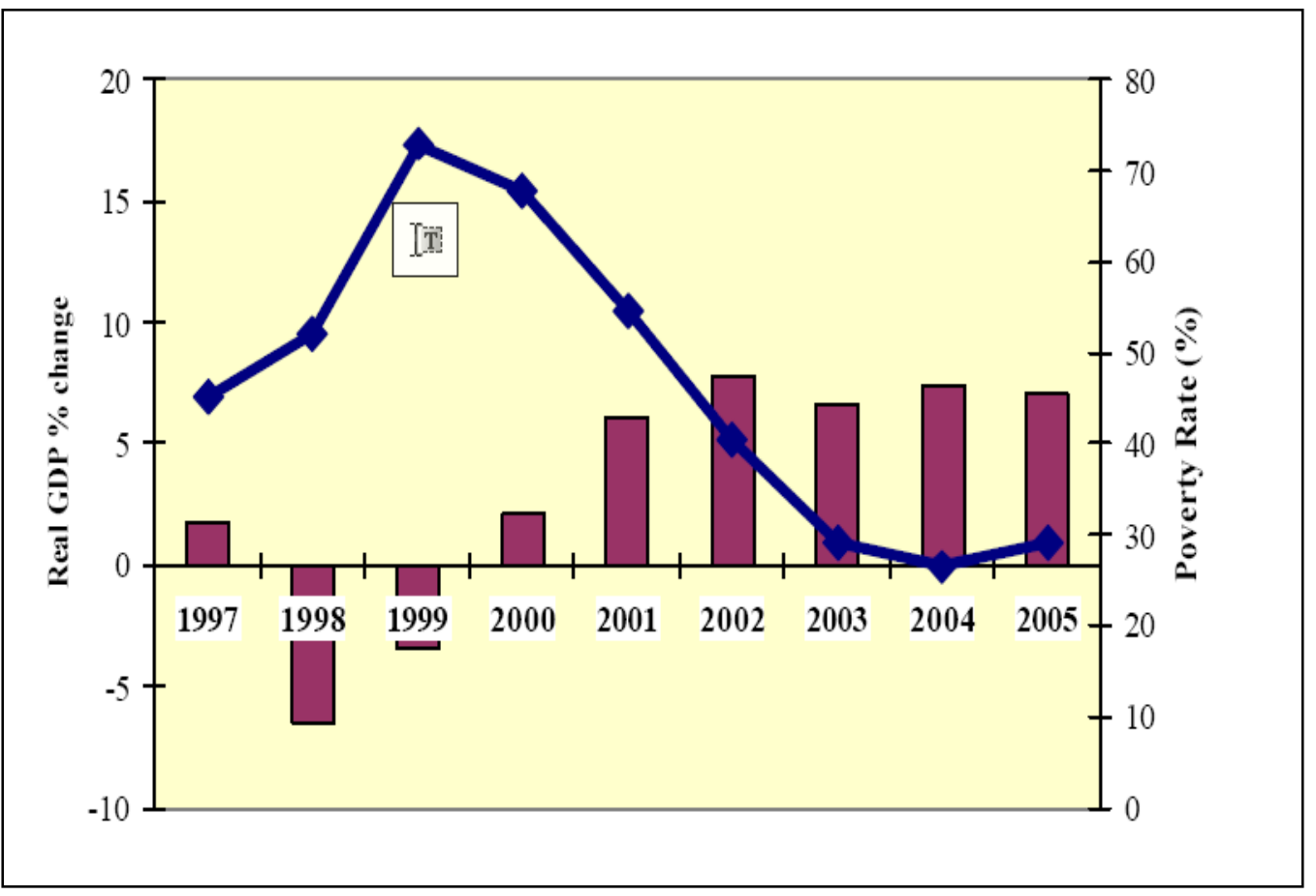

Source: National Bank of Moldova (Note: 2005 GDP growth is for Q1-Q3). 
Figure 3: Labour Force Survey Estimates on the number of migrants (in thousands) abroad between 1999-2005

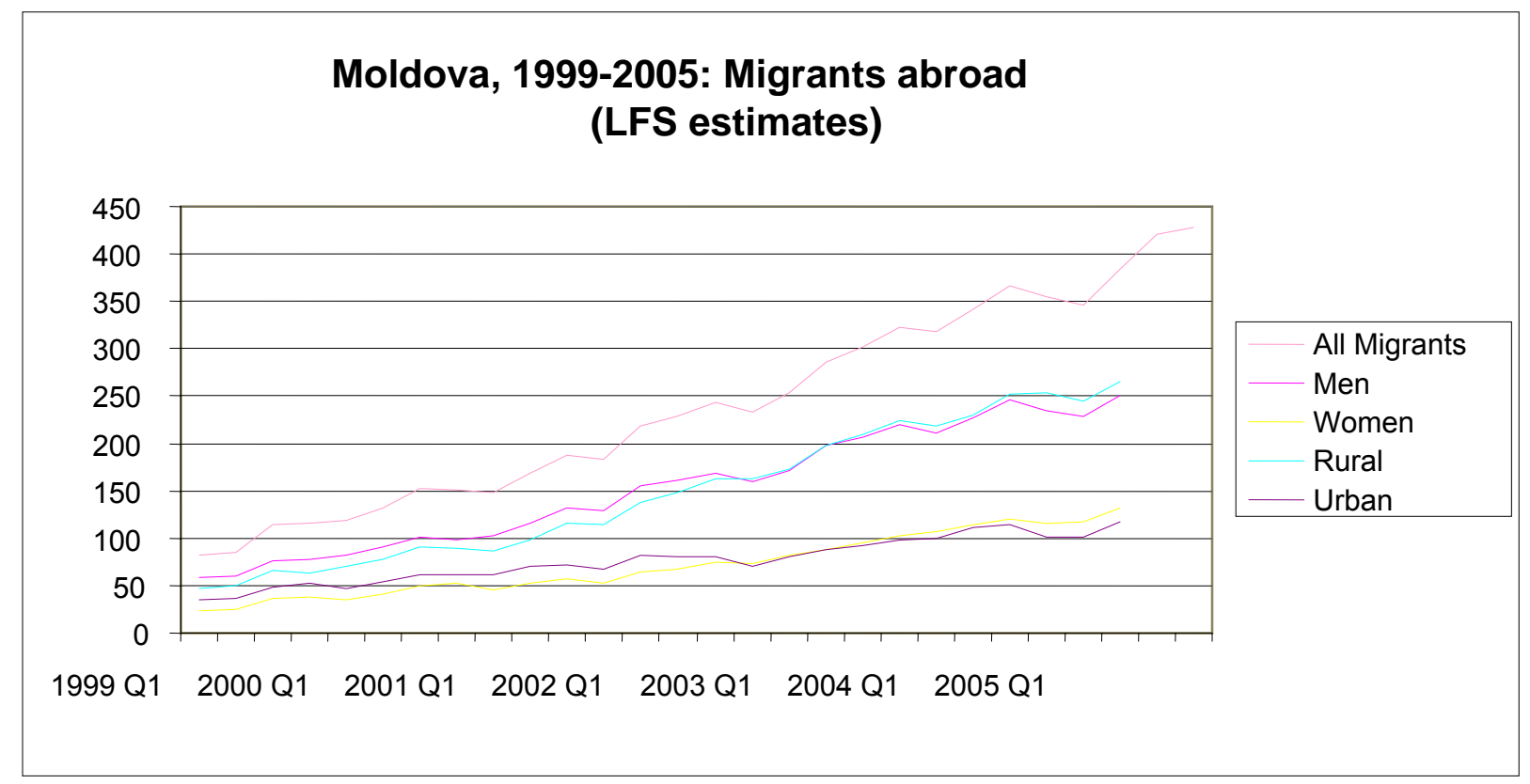

Source: National Bank of Moldova

Figure 4: Level of remittances (US \$ Million), 2000-2008

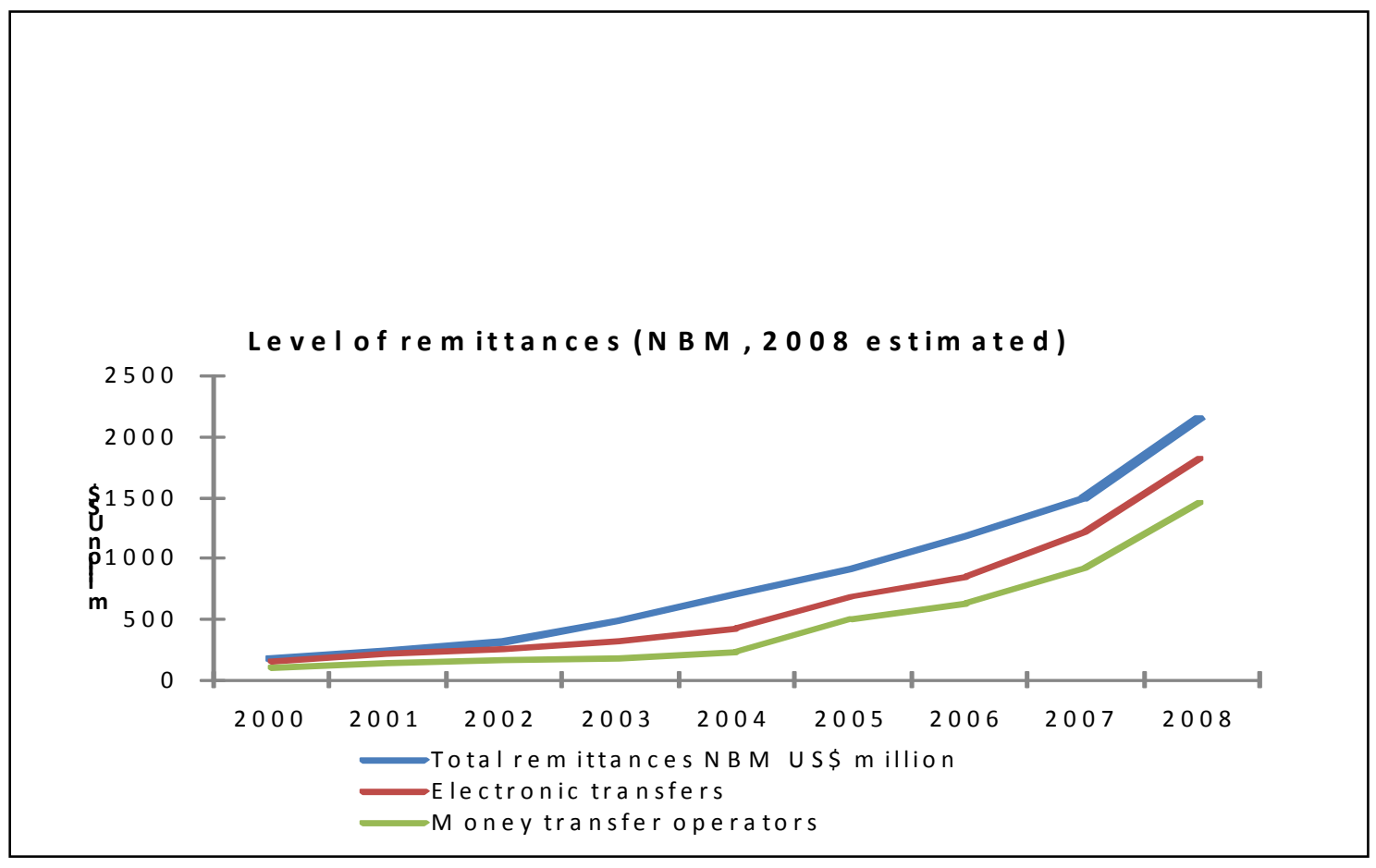

Source: National Bank of Moldova 
Table 1: Summary Statistics

\begin{tabular}{|c|c|c|c|}
\hline Variables & Variable Description & (1) & (2) \\
\hline $\begin{array}{l}\text { Income of the Household } \\
\text { (Satisfactory) }\end{array}$ & $\begin{array}{l}=0 \text { if household perceived its general income status as very bad , bad prior to the migrant leaving the household; } 1 \\
\text { if household perceived its general income status as satisfactory prior to the migrant leaving the household }\end{array}$ & .409 & .422 \\
\hline $\begin{array}{l}\text { Income of the Household } \\
\text { (good/V.good) }\end{array}$ & $=2$ if household perceived its general income status as very good or good prior to the migrant leaving the household & .168 & .183 \\
\hline Wealthy $\mathrm{Hh}$ & $=1$ If hh owns land/apartment + vehicle $\&>4$ durables & .064 & .0693 \\
\hline Region of Residence & $=1$ If household in urban area; 0 if in a rural area & .275 & .261 \\
\hline Presence of children & $=1$ if presence of members in household below 15 years of age; & .516 & .440 \\
\hline HOH_Age & Head of the household's age in years & 44.13 & 46.88 \\
\hline $\mathrm{HOH}$ _gender & $=1$ if female & .630 & .590 \\
\hline $\begin{array}{l}\text { Presence of other migrants in } \\
\text { the household }\end{array}$ & $=1$ if household has more than one migrant & .273 & .356 \\
\hline Migrant's Age & Migrant's age (in years) & 34.71 & 33.50 \\
\hline Migrant's Gender & Migrant's gender $($ male $=0)$ & .433 & .40 \\
\hline Migrant's Education & Migrant's education (in years) & 3.64 & 3.59 \\
\hline Migrant $\mathrm{HOH}$ & $=1$ if migrant is the head of household; 0 otherwise & .588 & .503 \\
\hline Intent to stay less than a year & $=1$ if migrants intents to stay less than a year in the destination country; 0 if intends to stay more than a year & .588 & .715 \\
\hline NELM & $=1$ if the individual trusts the eco environment in Moldova & .409 & .196 \\
\hline Network & $=1$ if has networks abroad, 0 otherwise & .805 & .715 \\
\hline $\mathrm{N}$ & Number of Observations & 498 & 447 \\
\hline
\end{tabular}




\section{Table 2: Two-Part Model and Heckman Selection Model}

\begin{tabular}{llcl}
\hline Two- Part & \multicolumn{3}{c}{ Selection } \\
\hline$(1)$ & $(2)$ & $(3)$ & $(4)$ \\
Participation & Level & Participation & Level \\
\hline
\end{tabular}

\section{Household Characteristics}

$H H$ subjective income status ${ }^{i}$

- Satisfactory

$\begin{array}{llll}-0.0306 & -0.0497 & -0.0730 & -0.0365 \\ (-0.82) & (-0.49) & (-0.77) & (-0.35) \\ -0.082^{*} & 0.0005 & -0.203 & 0.0421 \\ (-1.70) & (-0.00) & (-1.66) & (0.29) \\ -0.0451 & 0.230 & -0.106 & 0.255 \\ (-0.64) & (1.15) & (-0.60) & (1.27) \\ 0.00822 & -0.0701 & 0.0179 & -0.0673 \\ (0.20) & (-0.62) & (0.17) & (-0.61) \\ 0.0264 & 0.206^{*} & 0.0617 & 0.195 \\ (0.71) & (2.02) & (0.66) & (1.87) \\ -0.00171 & 0.0113^{*} & -0.00421 & -0.0108^{*} \\ (-0.97) & (-2.33) & (-0.95) & (-2.14) \\ -0.0208 & -0.0353 & -0.0543 & -0.0361 \\ (-0.41) & (-0.25) & (-0.43) & (-0.26) \\ -0.163^{* * *} & -0.0472 & -0.399^{* *} & \\ (-3.54) & (-0.34) & (-3.27) & \end{array}$

Migrant Individual

- Good/Very good

Wealth Status ${ }^{\text {ii }}$

Region of Residence

Presence of children below $15 \mathrm{yrs}$

$\mathrm{HOH}$ age

HOH_Gender $($ Female $=1)$

Characteristics

Migrant's Age

$0.000691 \quad 0.0078$

$-0.00156$

0.00860

Migrant's Gender $($ Female $=1)$

$(-0.33)$

(1.38)

$(-0.30)$

$0.221^{*}$

(2.02)

0.133

(2.14)

Migrants Education Level

$-0.00532$

$(1.09)$

$-0.0131$

$(-0.26)$

0.157

$(-0.27)$

(2.66)

Migrant $\mathrm{HOH}$ (dummy=1 if yes)

0.0350

0.0382

0.0900

(2.82)

$(0.50)$

Migrant Main Earner

$0.119^{*}$

$(0.19)$

(2.48)

0.131

$(0.51)$

$0.308^{*}$

Intent to stay less than a year

$-0.149^{* * *}$

$(0.98)$

(2.56)

$(-4.17)$

$0.300^{* *}$

$-0.375^{* * *}$

(1.65)

\section{Community Characteristics}

$(-3.02)$

$(-4.05)$

\section{$-0.262^{*}$}

$(-1.96)$

$\begin{array}{lllll}\text { NELM } & 0.237^{* * *} & 0.40^{* * *} & 0.616^{* * *} & 0.295 \\ & (6.89) & (4.23) & (6.53) & (1.78) \\ \text { Presence of networks abroad } & 0.0770 & 0.311^{* *} & 0.192 & 0.284^{*} \\ & (1.92) & (2.63) & (1.91) & (2.20) \\ \text { Observations } & 945 & 498 & 945 & 498 \\ \text { Rho } & & & .64 & \\ & & & (.4224)\end{array}$

Notes: (i) It is the reported perceived income status of a household measured on a scale of 1 to 5 , where $1=$ very poor and $5=$ very good.The reference category in our case of very poor economic status; (ii) A household is considered wealthy if hh owns land/apartment + vehicle and has more than four of the listed durables (washing machine, microwave oven, television, cable television, TV satellite dish, home telephone, mobile phone, computer, gas; * significant at $10 \%$; ** significant at $5 \%$; ** significant at $1 \%$. 


\section{Table 3: Specification Tests}

\begin{tabular}{|c|c|c|c|c|c|}
\hline \multicolumn{2}{|c|}{ Pooled Sample } & \multicolumn{2}{|c|}{ Low-Migration } & \multicolumn{2}{|c|}{ High Migration } \\
\hline $\begin{array}{l}\text { Partici } \\
\text { Pation }\end{array}$ & Level & $\begin{array}{l}\text { Partici } \\
\text { pation }\end{array}$ & Level & $\begin{array}{l}\text { Partici } \\
\text { pation }\end{array}$ & Level \\
\hline
\end{tabular}

\section{Household Characteristics}

HH subjective income status ${ }^{i}$

- Satisfactory

- Good/Verygood

Wealth Status ${ }^{\text {ii }}$

Region of Residence (Ref:Urban)

Presence of children below 15 yrs

$\mathrm{HOH} \_$age

HOH_Gender (Ref: Female)

Presence of other migrants in $\mathrm{HH}$

Migrant Individual Characteristics

Migrant's Age

Migrant's Gender (Ref: Female)

Migrant's Education Level

Migrant $\mathrm{HOH}(=1$ if yes)

Migrant Main Earner

Intent to stay less than a year

\section{Community Characteristics}

NELM

Presence of networks

Observations

$R^{2}$

$\begin{array}{llllll}0.0770 & -0.0497 & -0.384 & 0.0983 & 0.0154 & -0.136 \\ (-0.82) & (-0.49) & (-1.89) & (0.40) & (0.14) & (-1.18) \\ -0.207 & -0.0006 & -0.498^{*} & 0.425 & -0.0988 & -0.146 \\ (-1.70) & (-0.00) & (-2.02) & (1.44) & (-0.69) & (-0.95) \\ -0.113 & 0.230 & 0.241 & 0.320 & -0.286 & 0.273 \\ (-0.64) & (1.15) & (0.77) & (0.87) & (-1.28) & (1.06) \\ 0.0207 & -0.0701 & 0.0076 & 0.0273 & 0.0844 & -0.0868 \\ (0.20) & (-0.62) & (0.04) & (0.11) & (0.66) & (-0.63) \\ 0.0664 & 0.206^{*} & -0.0120 & 0.243 & 0.0978 & 0.149 \\ (0.71) & (2.02) & (-0.06) & (1.01) & (0.89) & (1.28) \\ 0.0043 & -0.0113^{*} & -0.0094 & 0.0062 & -0.002 & -0.014^{* *} \\ (-0.97) & (-2.33) & (-0.94) & (-0.54) & (-0.43) & (-2.67) \\ 0.0523 & -0.0353 & -0.229 & -0.320 & -0.0229 & 0.0137 \\ (-0.41) & (-0.25) & (-0.84) & (-0.99) & (-0.16) & (0.09) \\ -0.4^{* * *} & -0.0472 & -0.0513 & 0.0140 & -0.53^{* * *} & -0.0314 \\ (-3.49) & (-0.34) & (-0.20) & (-0.04) & (-3.84) & (-0.20) \\ & & & & & \\ 0.0017 & 0.00787 & 0.0082 & 0.0085 & -0.0043 & 0.0083 \\ (-0.33) & (1.38) & (0.76) & (0.63) & (-0.70) & (1.28) \\ 0.210^{*} & 0.133 & 0.380 & -0.110 & 0.138 & 0.226 \\ (2.01) & (1.09) & (1.59) & (-0.36) & (1.15) & (1.64) \\ 0.0134 & 0.150^{* *} & -0.0998 & 0.254 & -0.0038 & 0.120 \\ (-0.27) & (2.66) & (-0.94) & (1.82) & (-0.07) & (1.91) \\ 0.0879 & 0.0382 & 0.141 & 0.203 & 0.116 & -0.014 \\ (0.50) & (0.19) & (0.36) & (0.42) & (0.57) & (-0.06) \\ 0.300^{*} & 0.131 & 0.244 & 0.331 & 0.315^{*} & 0.0664 \\ (2.47) & (0.98) & (0.91) & (1.13) & (2.23) & (0.43) \\ -0.4^{* * *} & -0.300^{* *} & -0.0317 & -0.142 & -0.52^{* * *} & -0.32^{* *} \\ (-4.09) & (-3.02) & (-0.17) & (-0.61) & (-4.71) & (-2.86) \\ & & & & & \\ 0.62^{* * *} & 0.403^{* * *} & 1.1)^{* * *} & 0.715^{* *} & 0.51^{* * *} & 0.303^{* *} \\ (6.52) & (4.23) & (4.88) & (3.16) & (4.72) & (2.85) \\ 0.193 & 0.311^{* *} & 0.0411 & 0.0996 & 0.225^{*} & 0.347^{* *} \\ (1.92) & (2.63) & (0.18) & (0.36) & (1.96) & (2.61) \\ 945 & 498 & 226 & 114 & 719 & 384 \\ & 0.154 & & 0.258 & & 0.154 \\ & & & & & \\ & & & \end{array}$

Notes: (i) It is the reported perceived income status of a household measured on a scale of 1 to 5 , where $1=$ very poor and $5=$ very good.The reference category in our case of very poor economic status; (ii) A household is considered wealthy if hh owns land/apartment + vehicle and has more than four of the listed durables (washing machine, microwave oven, television, cable television, TV satellite dish, home telephone, mobile phone, computer, gas; ; $*$ significant at $10 \%$; ** significant at $5 \% ; * * *$ significant at $1 \%$. 


\begin{tabular}{llll}
\multicolumn{2}{c}{ Russia } & \multicolumn{2}{c}{ Other Countries } \\
\hline$(1)$ & $(2)$ & $(3)$ & $(4)$ \\
Participation & Level & Participation & Level \\
\hline
\end{tabular}

\section{Household Characteristics}

HH subjective income status ${ }^{i}$

- Satisfactory

- Good/Very Good

$\begin{array}{llll}-0.00305 & -0.128 & -0.0791 & -0.00180 \\ (-0.06) & (-0.98) & (-1.33) & (-0.01) \\ 0.00860 & 0.00337 & -0.197^{* *} & -0.0237 \\ (0.13) & (0.02) & (-2.70) & (-0.11) \\ -0.0602 & 0.0191 & -0.00682 & 0.561^{*} \\ (-0.60) & (0.07) & (-0.07) & (2.00) \\ 0.0179 & -0.0481 & -0.0103 & -0.176 \\ (0.31) & (-0.30) & (-0.17) & (-1.11) \\ 0.0738 & 0.364^{* *} & -0.0309 & 0.0351 \\ (1.50) & (2.75) & (-0.54) & (0.22) \\ -0.000277 & 0.00527 & -0.00184 & -0.0134 \\ (-0.11) & (-0.76) & (-0.70) & (-1.94) \\ -0.0210 & 0.132 & -0.0253 & -0.149 \\ (-0.32) & (0.70) & (-0.32) & (-0.70) \\ -0.187^{* *} & -0.105 & -0.122 & 0.0266 \\ (-3.10) & (-0.56) & (-1.69) & (0.13)\end{array}$

Migrant Individual Characteristics

Wealth Status ${ }^{\mathrm{ii}}$

Region of Residence (Ref:Urban)

Presence of Children below 15 yrs

$\mathrm{HOH} \_$age

HOH_Gender (Ref: Female)

Presence of other migrants in $\mathrm{HH}$

Migrant's Age

Migrant's Gender (Ref: Female)

$-0.000740$

0.00853

$(-0.26)$

$(1.12)$

0.0219

$0.357^{*}$

$(0.39)$

(2.18)

Migrant's Education Level

$-0.0156$

0.151

$(-0.53)$

(1.87)

Migrant $\mathrm{HOH}$ (=1 if yes)

0.121

(1.29)

0.172

0.0767

$(0.62)$

Migrant Main Earner

(1.17)

Intent to stay less than a year

0.0479

$-0.00228$

0.00652

$-0.130^{*}$

$(0.26)$

$-0.000740$

0.291

$(-0.74)$

(0.76)

$0.148^{*}$

$-0.217$

(2.27)

$(-1.18)$

$-0.00551$

0.0809

$(-0.20)$

(1.00)

$-0.0528$

0.0647

$(-0.49)$

$(0.22)$

$0.191^{* *}$

0.220

(2.62)

$-0.113^{*}$

(1.14)

0.00853

$-0.00228$

$-0.538^{* * *}$

\section{Community Characteristics}

NELM
Presence of networks abroad
Observations
$R^{2}$

$0.211^{* * *}$
$(4.47)$
$0.106^{*}$
$(2.10)$
555

$0.332^{* *}$

$0.268^{* * *}$

$0.434^{* *}$

(2.69)

(5.20)

(2.86)

$0.381^{*}$

0.0361

0.295

(2.56)

(0.54)

(1.57)

272

390

226

0.212

0.206

Notes: (i) It is the reported perceived income status of a household measured on a scale of 1 to 5 , where $1=$ very poor and $5=$ very good.The reference category in our case of very poor economic status. (ii) A household is considered wealthy if hh owns land/apartment + vehicle and has more than four of the listed durables (washing machine, microwave oven, television, cable television, TV satellite dish, home telephone, mobile phone, computer, gas. ; $*$ significant at $10 \%$; ** significant at $5 \% ; * * *$ significant at $1 \%$. 


\section{Table A1: Tobit Model}

\section{APPENDIX}

(1)

Coefficient
(2)

$\mathrm{E}(\mathrm{R} \mid \mathrm{x}, \mathrm{R}>0)$
(3)

$\mathrm{R}(\mathrm{R} \mid \mathrm{x})$

\section{Household Characteristics}

$H H$ subjective income status ${ }^{I}$

- Satisfactory

$\begin{array}{lll}-0.388 & -0.166 & -0.0274 \\ (-0.90) & (-0.91) & (-0.90) \\ -0.916 & -0.381 & -0.0654 \\ (-1.64) & (-1.69) & (-1.62) \\ -0.312 & -0.132 & -0.0222 \\ (-0.38) & (-0.39) & (-0.38) \\ 0.0423 & 0.0182 & 0.00298 \\ (0.09) & (0.09) & (0.09) \\ 0.399 & 0.171 & 0.0281 \\ (0.93) & (0.93) & (0.93) \\ -0.0243 & -0.0104 & -0.0017 \\ (-1.20) & (-1.20) & (-1.20) \\ -0.237 & -0.102 & -0.0167 \\ (-0.41) & (-0.41) & (-0.41) \\ -1.958^{* * *} & -0.809^{* * *} & -0.14^{* * *} \\ (-3.54) & (-3.68) & (-3.52)\end{array}$

Migrant Individual Characteristics

- Good/Verygood

Wealth Status ${ }^{2}$

Region of Residence (Ref:Urban)

Presence of children below 15 yrs

$\mathrm{HOH} \_a g e$

HOH_Gender (Ref: Female)

Presence of other migrants in the $\mathrm{HH}$

Migrant's Age

Migrant's Gender (Ref:Female)

Migrants Education Level

Migrant $\mathrm{HOH}(=1$ if yes)

Migrant Main Earner

Intent to stay less than a year

Community Characteristics

NELM

Presence of networks abroad

Observations

$\begin{array}{lll}-0.00448 & -0.00192 & -0.0003 \\ (-0.19) & (-0.19) & (-0.19) \\ 1.090^{*} & 0.473^{*} & 0.0764^{*} \\ (2.23) & (2.21) & (2.25) \\ 0.0264 & 0.0113 & 0.00186 \\ (0.11) & (0.11) & (0.11) \\ 0.584 & 0.250 & 0.0413 \\ (0.71) & (0.72) & (0.71) \\ 1.403^{*} & 0.586^{* *} & 0.0999^{*} \\ (2.53) & (2.60) & (2.51) \\ -1.868^{* * *} & -0.827^{* * *} & -0.13^{* * *} \\ (-4.46) & (-4.33) & (-4.57)\end{array}$

$\begin{array}{lll}2.953^{* * *} & 1.350^{* * *} & 0.199^{* * *} \\ (7.08) & (6.69) & (7.49) \\ 1.093^{*} & 0.455^{*} & 0.0780^{*} \\ (2.27) & (2.35) & (2.25) \\ 945 & 945 & 945\end{array}$

Notes: (i) It is the reported perceived income status of a household measured on a scale of 1 to 5 , where $1=$ very poor and $5=$ very good.The reference category in our case of very poor economic status; (ii) A household is considered wealthy if hh owns land/apartment + vehicle and has more than four of the listed durables (washing machine, microwave oven, television, cable television, TV satellite dish, home telephone, mobile phone, computer, gas; ; $*$ significant at $10 \%$; * significant at $5 \%$; *** significant at $1 \%$. 